\title{
PROVA JUDICIÁRIA, VERDADE E ESTILO NA PRODUÇÃO DO DISCURSO JURÍDICO: ELEMENTOS PARA UMA TIPIFICAÇÃO
}

ARUANÃ ANTONIO DOS PASSOS 


\title{
PROVA JUDICIÁRIA, VERDADE E ESTILO NA PRODUÇÃO DO DISCURSO JURÍDICO: ELEMENTOS PARA UMA TIPIFICAÇÃO
}

Aruanã Antonio dos Passos ${ }^{1}$

\section{RESUMO}

Busca-se analisar, por meio de processo-crime executado na Comarca de Clevelândia, interior do Paraná, no início do século XX, um contínuo linear de fragmentos de vidas. Vidas que de algum modo confrontaram-se com o aparelho judiciário. A expressão no presente desse encontro (o processo-crime) pertence ao domínio de uma prática de poder discursiva, típica do Poder Judiciário. O elemento constitutivo da prova jurídica em nível discursivo é um dispositivo de estratificação linear que acaba se apropriando dos acontecimentos em nome de determinada ordem que dá forma, característica ao seu léxico, ao seu estilo e interfere no destino de seus personagens. Assim, pretende-se contribuir para uma análise de processos jurídicos que considere as sensibilidades infiltradas nas ações, tanto da racionalidade jurídica quanto da impulsividade da violência.

Palavras-chave: Processo-crime. Verdade. Discurso jurídico.

\begin{abstract}
We analyze through criminal proceedings in the District of Clevelândia executed within the Paraná at the beginning of sec. XX be a continuous linear fragments of life. Lives that somehow clashed with the judiciary. The expression on present this meeting (the criminal case) belongs to the domain of a discursive practice, typical power of the judiciary. The constitutive element of legal proof the discursive level is a linear device stratification that just appropriating the events on behalf of a certain

1 Docente do Curso de História da Universidade Estadual de Goiás (UEG), Unidade Universitária de Goiás. Doutorando em História pela Universidade Federal de Goiás (UFG). Autor de Leviatã no Sertão: Crime, Justiça e Violência no interior do Paraná (Juruá, 2012), e Forças de Dominação: intelectuais e sertanejos na Guerra do Contestado (Appris, 2014). aruana. ap@gmail.com.
\end{abstract}


order forming characteristic to its lexicon, its style and interferes with the fate of their characters. Thus, we intend to contribute to an analysis of legal processes that take into account the sensitivities infiltrated actions, both legal rationality as the impulsiveness of violence.

Keywords: Criminal proceedings. Thuth. Legal discourse.

\section{UMA TRAMA ENIGMÁTICA}

Ao final da tarde de 19 de maio de 1921, Pantaleão José de Medeiros preparava-se para jantar com sua mulher e filhos. No mesmo momento Saturnino Ignácio Cardoso dirigia- se à casa de Pantaleão. E o que poderia ser apenas uma conversa rápida entre patrão e empregado ou entre amigos em instantes assumiria, para um, a certeza de antecipação inevitável da abreviação da vida, e para o outro dali pra frente, o silêncio enigmático do processo-crime.

Ao chegar a casa de Pantaleão, Saturnino logo se identificou:

- Licença seu Pantaleão?!

No mesmo instante Pantaleão abandona a mesa, pega sua winchester e vai até a porta da casa, ao encontro de Saturnino. Ernesta Maria de Medeiros, mulher de Pantaleão, chegou a ouvir alguém no pátio da casa, e mesmo vendo seu marido interromper o jantar e ir ao encontro da visita de posse de sua arma, talvez nem imaginasse o que se passaria em instantes. 
Ao chegar ao pátio, Pantaleão, sem meio termo, responde ao chamado de Saturnino:

- A licença que te dou é essa, filho da puta!

Os dois primeiros tiros prostram Saturnino ao chão. Pantaleão se aproxima da vítima e, ao se encararem, o que se sabe é que o pedido de Saturnino, para que Pantaleão the poupasse a vida, não foi capaz de impedir o terceiro tiro. Sem mais, Pantaleão se dirige a sua mulher, diz a ela que o espere e não se preocupe. Daí então pegou seu cavalo e fugiu.

Saturnino é socorrido primeiramente pela esposa de Pantaleão, que manda seus filhos até o vizinho mais próximo pedirem ajuda. Algum tempo depois, José Ayres de Arruda chega à casa de Ernesta. Diria ele depois que os filhos de Pantaleão chegaram a sua casa chorando e lhe disseram que seu pai havia matado a tiros Saturnino. Sem demora, dirige-se ao local e encontra seu conhecido Saturnino "caído ao solo", "esvaindose em sangue". Provavelmente com a ajuda de Vicente Claudio dos Santos e de Ernesta, os três, então, recolheram a vítima até a cozinha da casa de Pantaleão. Saturnino sobreviveria aos ferimentos ainda quinze dias antes de falecer.

No dia 31 do mesmo mês, o adjunto de promotor público do município de Clevelândia, interior do Paraná, Ernesto Araujo de Góes, inicia o processo com a denúncia do "facto delictuoso" (ESTADO DO PARANÁ, Processo-crime contra Pantaleão José de Medeiros, 1921). Inicia-se, a partir de então, 
a construção da verdade jurídica.

\section{PROVA JUDICIÁRIA}

Essa pequena narração trágica extraída de um processocrime do início do século, executado no interior do Paraná sob circunstâncias que já foram reduzidas pela força do tempo, contém em si, como todo acontecimento histórico, um contínuo linear de fragmentos de vidas obscuras, vidas que de algum modo se confrontaram com um poder ou, por outro lado, exigiram que esse poder o socorresse ou ainda o beneficiasse de algum infortúnio. Trata-se de seu encontro ou confronto com o aparelho judiciário, ou com a justiça. Assim, tudo aqui foi observado através de um olho do poder; é dessa forma que o processo-crime pertence ao domínio de uma prática de poder discursiva, típica do poder judiciário: "As práticas judiciárias (...) me parecem uma das formas pelas quais nossa sociedade definiu tipos de subjetividade, formas de saber e, por conseguinte, relações entre o homem e a verdade que merecem ser estudadas (FOUCAULT, 2002, p.11).

É justamente em torno das relações diversas existentes no processo jurídico para a autenticação de uma verdade em torno de um acontecimento que se configura geralmente como fratura no campo social, que se buscará analisar o processo construído em torno do assassinato de Saturnino por Pantaleão. Inicialmente, concorda-se com Foucault quando afirma que: 
O inquérito é precisamente uma forma política, uma forma de gestão, de exercício do poder que, por meio da instituição judiciária, veio a ser uma maneira, na cultura ocidental, de autenticar a verdade, de adquirir coisas que vão ser consideradas e de as transmitir. O inquérito é uma forma de saber-poder (FOUCAULT, 2002, p.78.).

Masa autenticação da verdade no processonão se concentra apenas numa luta simbólica ou discursiva. Essa autenticação da verdade passa pela imagem-teatro do espetáculo retórico do saber-poder jurídico, como também engendra o embate entre a produção de conhecimento e formas de estruturação de capitais econômicos, políticos, sociais e sentimentais. Mas o historiador só possui um monumento-discurso pelo qual busca empreender a compreensão dos acontecimentos históricos que só podem ser percebidos por meio de sua efetivação em estados de coisas (DELEUZE, 1992, p.210), tal qual o reflexo de um espelho estilhaçado pelo tempo, pelo esquecimento. Mas o discurso jurídico não possui um reflexo ideológico em estado puro que seja capaz de tornar possível a extração de qualquer variante linguística ou mesmo universal conceitual, justamente porque a carga ideológica é a poeira da batalha, tal como enunciou outrora Foucault. O que nos escapa é o devir do acontecimento, a experimentação é percebida, mas ela não é a história. Em outras palavras, constata-se haver, também, no discurso jurídico uma série de procedimentos de controle e delimitação do discurso ora analisados por Foucault n'A Ordem do Discurso. Procedimentos esses de duas naturezas: internos e externos, e 
exemplificados com três exemplos-modelo: a palavra proibida, a segregação da loucura e a vontade de verdade.

A todos os elementos constituídos pelas regras, procedimentos, condições a priori, contextos, relações que tornam possível a existência do próprio discurso; o conjunto de aspectos presentes nos jogos de poder que circunscrevem, seccionam, ramificam e produzem os discursos: a isso Foucault chama de "ordem do discurso". É a inserção profunda do discurso em relações de poder e saber que o produz e o torna possível de ser enunciado. Por outro lado, não é a sujeição completa nem mesmo o apagamento do sujeito-enunciador diante de todas essas condições, muito menos a onipresença do "produto final" da interação comunicativa (o discurso).

A relação linguística significante-significado foi, sem dúvida, concebida de maneiras muito diversas: ora como arbitrária, ora como necessária, da mesma forma que o verso e o anverso de uma mesma folha, ora como correspondente termo a termo, ora globalmente, ora como sendo tão ambivalente que não se pode mais distingui-los. De qualquer modo, o significado não existe fora de sua relação com o significante, e o significado último é a própria existência do significante que se extrapola para além do signo. Sobre o significante, só se pode dizer uma coisa: ele é a redundância, o redundante, devido ao seu incrível despotismo e ao sucesso alcançado. $\mathrm{O}$ arbitrário, o necessário, $\mathrm{o}$ correspondente termo a termo ou global e o ambivalente servem a uma mesma causa que comporta a redução do conteúdo ao significado e a redução da expressão ao significante. Ora, as 
formas de conteúdo e as formas de expressão são eminentemente relativas e estão sempre em estado de pressuposição recíproca; mantêm correlações biunívocas, exteriores e "disformes" entre seus respectivos segmentos; não há jamais conformidade entre ambas, nem de uma à outra, mas há sempre independência e distinção reais; para ajustar uma das formas à outra e para determinar as correlações, é preciso mesmo um agenciamento específico variável. Nenhum desses caracteres convém à relação significante-significado, mesmo se alguns parecerem manter com ela uma espécie de coincidência parcial e acidental, e o conjunto dos caracteres se opuser radicalmente ao quadro do significante. Uma forma de conteúdo não é significado, do mesmo modo que uma forma de expressão não é significante. Isso é verdadeiro para todos os estratos, inclusive para aqueles em que intervém a linguagem (DELEUZE, G. \& GUATARRI, F., 1994, p. 81).

Trata-se aqui de buscar a superação dessa dicotomia pela percepção dos sujeitos presentes no discurso jurídico considerando-se os procedimentos de controle e sujeição dos discursos - por meio da imanência dos efeitos de sentido capazes de desvelar aos nossos olhos esses sujeitos "infames" os quais se confrontaram com esse poder, do modo com que tiveram de se localizar diante dos feixes de poder e das linhas de fuga que criaram em nome de suas expectativas e objetivos, em relação aos seus crimes ou às dores que lhe foram impressas por vezes de modo irreversível.

Foucault mostra toda uma série de procedimentos internos e externos de sujeição e produção dos discursos. Dessa forma, os 
procedimentos chamados externos "funcionam como sistemas de exclusão; concernem, sem dúvida, à parte do discurso que põe em jogo o poder e o desejo" (FOUCAULT, 2005, p.21). Se as práticas discursivas revelam que o conteúdo não se reduz ao significado é sob esse aspecto que se torna possível uma análise dos acontecimentos descontínuos, essas "cesuras que rompem o instante e dispersam o sujeito em uma pluralidade de posições e de funções possíveis" (FOUCAULT, 2005, p.58) em que, muitas vezes, a vida e a morte se decidem.

É sobre esses elementos gerais que se demarca a enunciação, a produção mesma do discurso jurídico que a prova surge como o centro do processo-crime. Os elementos externos de sujeição dos discursos aqui são seccionados pela subjetividade dos enunciadores e dos enunciatários e pelos efeitos de sentido produzidos pelos procedimentos de exclusão, produção e sujeição do discurso. A prova jurídica é construída pelo confronto de uma série de discursos em torno de um ou vários não discursos (acontecimentos), cada versão permeada de subjetividade e parcialidade, "a prova" então é produto da análise da série de indícios e agravantes resgatados em torno dos fatos.

Por vezes a racionalização efetivada por meio do processo homogeneíza toda subjetividade e parcialidade, e a sua linearidade discursiva tem a função de dar consistência aos diversos elementos inerentes à enunciação e aos efeitos de sentido: testemunhos, provas materiais, exames de corpo delito, uso do Código de Leis, o exercício legítimo do poder instituído 
aos magistrados etc. $\mathrm{O}$ grande elemento constitutivo da prova jurídica em nível discursivo é esse dispositivo de estratificação linear que, ao dessubstanciar os discursos, acaba se apropriando destes em nome de determinada ordem sujeita a procedimentos de exclusão desses mesmos discursos e que dão forma característica ao seu léxico, ao seu estilo. Em outras palavras, a enunciação, o indivíduo e a interação verbal entre emissor e receptor no processo-crime são profundamente "condicionados" pela instituição e seus aparelhos de captura (processo-crime), ou seja, a produção de significação pelos sujeitos é minimizada por sua função em torno da necessidade da prova e da verdade. E sob esse aspecto perdem-se muitos elementos inerentes a essa espécie de formação discursiva: todos os elementos são condicionados (o lugar e a cena, a cenografia e a dêixis, o ethos etc. $)^{2}$.

Toda construção da verdade por meio do processo jurídico se dá pela apropriação de outros discursos. Assim, a verdade jurídica e a sua confiabilidade são construídas pela estratificação linear e sedimentação de uma série de outros discursos interpelados pelo aparelho judiciário que, em conjunto, dão forma ao seu estilo. Da aparente continuidade discursiva

2 “(...) porque o discurso possui sua própria ordem e é deste ponto de vista que é preciso avaliar o interesse dos aparelhos lingüísticos de que se utiliza". MAINGUENEAU, D. Novas tendências em análise do discurso. Campinas / São Paulo: Pontes, 1989, p.18. 
podem-se identificar várias cenas e dêixis em que há vários eutu ou nós e do aqui-agora: em cada inquérito, cada execução, atraso, intimação etc. (MAINGUENEAU, 1989, p.41.).

No caso jurídico, a documentação traz uma lacuna fundamental: o silêncio do acusado, um personagem elementar. Esse fato não pode ser desprezado porque no campo jurídico, para utilizar a terminologia de Pierre Bourdieu (BOURDIEU, 2000, p.209-254) ${ }^{3}$, e em especial, no processo-crime, as lutas se dão de diversas maneiras e envolvem todos os seus personagens, se há silêncio, há lacuna, e consequentemente a eventual prisão e o julgamento podem ser comprometidos. No entanto, uma série de elementos discursivos e não discursivos que engendram práticas no campo jurídico constituem a arena do conflito e do exercício do poder.

O elemento "disciplinar" do discurso jurídico, ou seja, a sua caracterização enquanto domínio de objetos com um corpus de proposições verdadeiras e universalmente válidas (leis); um jogo de regras e definições (interpelação, recurso, argumentação técnica, intermediação do acesso a

3 Levamos em consideração os elementos elencados por Bourdieu responsáveis pela constituição do campo jurídico (a divisão do trabalho, o monopólio instituído, em suma, a eficácia simbólica do direito e da justiça percebidos pelo estudioso através do campo jurídico. No entanto, Bourdieu se preocupa nesse texto com as características estruturantes e pouco com o discurso jurídico. Contrapomos então as considerações de Foucault em torno do aparelho jurídico e de suas análises em torno das formações discursivas e das relações entre saber-poder-verdade. Essa perspectiva quando cruzada com os documentos tornou possível uma insinuação em torno de uma análise do discurso jurídico que ultrapasse as classificações já tradicionais que levam em conta uma metodologia fundamentada numa tipologia dos crimes, através da compreensão dos silêncios, interdições, poderes, que se escondem por detrás dos fluxos discursivos aparentemente lineares. Assim, a classificação a priori dos acontecimentos violentos presentes nos processoscrime não satisfaz as condições de produção do próprio acontecimento do qual a justiça precisa tratar. 
esses dispositivos e consequentemente restrição do exercício do direito e do acesso à justiça a um corpo burocrático, funcional); de técnicas e de instruções. Assim, "trata-se de determinar as condições de seu funcionamento, de impor aos indivíduos que os pronunciam certo número de regras e assim de não permitir que todo mundo tenha acesso a eles" (FOUCAULT, 2005, 3637). O elemento disciplinar fica evidente porque, entre outras características, o processo só se inicia com a denúncia do adjunto de promotor que

a) comunica o crime;

b) utiliza parecer técnico e de informantes para construir a denúncia, e ainda

c) define e enquadra o crime no Código de Leis que prevê a pena.

offerece o Adjunto de Promotor Público a presente denúncia, para a fim de julgada provada, ser o denunciado punido com as penas do referido artigo. Assim pede a V.S. que, autoada esta proceda-se aos mais termos para a formação da c culpa, inquerindo-se as testemunhas arroladas (ESTADO DO PARANÁ. Comarca de Palmas. Juizo Municipal do Terno de Clevelândia. Processo-crime contra Pantaleão José de Medeiros. 1921. p. 2.)

O elemento ritualístico. Fundamentalmente os elementos rituais do discurso jurídico podem ser considerados performáticos na concepção de Bourdieu. Em outras palavras, 
não são elementos simbólicos que constituem uma retórica vazia que cumpriria uma função puramente representativa, mas teriam a função de agir como estruturas estruturantes do próprio discurso jurídico, do processo, da prova e da verdade: "os discursos religiosos, judiciários, terapêuticos e em parte também políticos não podem ser dissociados dessa prática de um ritual, ao mesmo tempo, propriedades singulares e papéis preestabelecidos" (FOUCAULT, 2005, 39).

Se tivéssemos de caracterizar o discurso jurídico, poderíamos verificar que ele possui tanto elementos de um discurso polêmico, em que há reversibilidade condicionada sob condições particulares, e de um discurso autoritário, no qual há assujeitamento ao comando: "jurou dizer a verdade do que soubesse e lhe fosse perguntado" (ESTADO DO PARANÁ. Comarca de Palmas. Juízo Municipal do Terno de Clevelândia. Processo-crime contra Pantaleão José de Medeiros. 1921), ou pelo menos um discurso que necessita da presença da autoridade para ser enunciado e para tornar a enunciação possível ${ }^{4}$ :

Este reconhecimento (...) só é atribuído gratuitamente sob certas condições, aquelas que definem o uso legítimo: deve ser pronunciado pela pessoa legitimada para fazê-lo (...); deve ser produzido em uma situação legítima, ou seja, diante de destinatários legítimos (não é possível ler um poema dadaísta em uma reunião do Con-

4 Segundo Jacques Derrida: “A justiça do direito, a justiça como direito não é a justiça. As leis não são justas como leis. Não obedecemos a elas porque são justas como leis. Não obedecemos a elas porque são justas, mas porque têm autoridade". In: DERRIDA, J. Força de Lei: o fundamento místico da autoridade. São Paulo: Martins Fontes, 2007, p.21. 
selho de Ministros); enfim, deve ser enunciado sob formas legítimas (sintáticas, fonéticas etc.).

A legitimação da autoridade do processo em si, dos magistrados e da sentença (no caso acima mencionado a sentença foi deferida, mas não se sabe se foi aplicada, sabe-se, apenas, que Pantaleão fugiu) mantém uma relação de reflexibilidade com a própria produção da prova e, nesse sentido, a construção da verdade e a execução da sentença pelo juiz é em sua grande maioria determinada pelos discursos produzidos pelas testemunhas. Cinco testemunhas fazem parte da constituição da verdade no processo contra Pantaleão. Uma delas é o primo-irmão do acusado e inspetor de quarteirão. Ele presenciou o acontecimento, estava lá, e não se pode afirmar que tenha ajudado na fuga. $\mathrm{O}$ que ele declara é que Pantaleão agiu com muita raiva e seu ato foi um ato de banditismo. Todas as outras testemunhas reafirmaram essa opinião. É o filtro discursivo jurídico agindo em nome da objetividade que busca a verdade sobre o acontecimento (Cf: BOURDIEU, P. et. al. MAINGUENEAU, 1989, p. 37). Além dessa opinião, outras constituem homologias frequentes em processos-crime, como que um questionário preexistente e aplicável tanto às testemunhas como a saberes específicos que fazem parte da trama (pareceres ad-hoc, por exemplo):

$1^{\mathrm{a}}$ testemunha: José Ayres de Arruda.

Disse: que no dia desenove do corrente as desessete horas em sua casa, quando os filhos meno- 
res de Pantaleão José de Medeiros, seu visinho, chorando, lhe disseram, que seu pai Pantaleão, havia morto com tiros, Saturnino; que imediatamente seguindo ao local, isto é a casa de Pantaleão, chegando ao terreiro notou que achava se cahido ao solo, seu conhecido, de nome Saturnino Ignacio Cardoso, offendido com diversos ferimentos e que esvahia se em sangue, que no local onde se encontrava a victima, encontrou se com a mulher do acusado que ao lhe fez mistério haver Pantaleão José de Medeiros, atirado com tensão de matar a victima Saturnino; sabe ao ser perguntado o crime, nenhuma discussão houve entre o crminoso e a victima; sabe ainda pela própria mulher do criminoso, que a victima ao entrar no terreiro da casa de Pantaleão, pediu licença para entrar, no que Pantaleão, lançando mão de uma Winchester, disselhe "a licença que te dou é esta, filho da puta" em acto contínuo, da porta de sua casa, deu-lhe tres tiros; declara ainda que Saturnino era camarada do criminoso, gosavam de boas relações, ignorando si ultimamente alguma desinteligência houve, entre o criminoso e a victima porem acha que o proceder de Pantaleào foi um acto de banditismo. E por nada mais saber, nem lhe ser perguntado, deu se por findo este depoimento, que depois de lido e achado conforme assigna com a autoridade, do que tudo dou fé. Eu $2^{\circ}$ Sargento Eusebio Carvalho de Oliveira, escrivão ad-hoc o escrevi (sic.) ( ESTADO DO PARANÁ. Comarca de Palmas. Juizo Municipal do Terno de Clevelândia. Processo-crime contra Pantaleão José de Medeiros. 1921, p. 9).

Os elementos contínuos identificados nas inquirições 
são: o que sabe do crime? $O$ que sabe da relação entre os envolvidos? E a opinião em relação ao acontecimento. Das cinco testemunhas, os elementos gerais do depoimento de José Ayres se mantêm, somente com a terceira testemunha é que haverá novo elemento que produz um novo efeito de sentido às causas do crime. João Paim das Rosas declara ter ouvido falar de uma tentativa de abuso da mulher de Saturnino "com propostas imoraes" por Pantaleão, enquanto aquele viajava. No entanto, o depoimento que modifica mais substancialmente qualquer hipótese em torno do acontecimento é justamente o da quinta e última testemunha. A esposa do réu, Ernesta Maria de Medeiros, disse em depoimento que

Saturnino era devedor de tresentos e tantos mil reis e que para não pagar a dívida protestava que Pantaleão tinha faltado com respeito a sua mulher; que embora Pantaleão seja seu marido acha que o mesmo procedeu mal andando fora da lei pois tinha outros meios para proceder contra Saturnino si houvesse motivo (sic). ( ESTADO DO PARANÁ. Comarca de Palmas. Juizo Municipal do Terno de Clevelândia. Processo-crime contra Pantaleão José de Medeiros. 1921, p. 14).

Há duas hipóteses possíveis para as motivações do crime, baseadas nos fragmentos de informação presentes no processo. Uma diz que Pantaleão tentou abusar, sim, da mulher de Saturnino; que Saturnino devia a Pantaleão algum dinheiro e se aproveitou do ato de Pantaleão para difamá-lo 
diante da comunidade e tomar proveito da situação. Pantaleão teria assassinado Saturnino porque não aguentava mais aquela condição que feria a sua honra perante sua própria família.

A outra versão possível pelo processo-crime diz que Pantaleão tentou se aproveitar da mulher de Saturnino e por ser seu patrão, conhecer a fragilidade inerente do aparelho judiciário e seu funcionamento, o modo com que se exercia a distribuição da justiça e das penas, apenas fugiu por algum tempo ciente de que poderia escapar de algum modo. De qualquer forma, a situação real ocultada, ou não, pela mulher de Pantaleão diz que no interior daquela família residiam os meios últimos capazes de fazer com que a ira de Pantaleão, essa paixão destrutiva, esse sentimento violento, dominasse-o apenas por alguns instantes e alterasse tantos destinos em nome de uma fatalidade manifesta, porque o conflito direto entre Pantaleão e Saturnino parece não ter sido capaz de desencadear todo esse ódio.

\section{REFERÊNCIAS}

BOURDIEU, P. O poder simbólico. 3. ed. Rio de Janeiro: Bertrand Brasil, 2000.

DELEUZE, G. Conversações (1972-1990). Rio de Janeiro: Ed. 34, 1992.

DERRIDA, J. Força de lei: o fundamento místico da autoridade. 
São Paulo: Martins Fontes, 2007.

\& GUATARRI, F. Mil platôs: capitalismo e esquizofrenia. Vol. 1. Rio de Janeiro: Ed. 34, 1994.

ESTADO DO PARANÁ. Comarca de Palmas. Juizo Municipal do Terno de Clevelândia. Processo-crime contra Pantaleão José de Medeiros. 1921.

FOUCAULT, M. A ordem do discurso. Aula inaugural no Collège de France, pronunciada a 2 de dezembro de 1970. 12. ed. São Paulo: Edições Loyola, 2005, p.21.

. A verdade e as formas jurídicas. 3. ed. Rio de Janeiro: Nau Editora, 2002.

MAINGUENEAU, D. Novas tendências em análise do discurso. Campinas / São Paulo: Pontes, 1989.

Recebido em: 26/05/2014

Aprovado em: 31/07/2014 